\title{
MEASUREMENT OF THE VARIATIONS IN CALCIFICATION IN NORMAL RABBIT BONE
}

\author{
Maureen Owen, Oxford, England
}

Nuffield Graduate Assistant, Nuffield Institute for Medical Research and Nuffield Department of Medicine, Oxford

It is now well known that the distribution of mineral salts in bone tissue is not uniform. This is strikingly demonstrated in microradiographs of transverse sections of bone (Amprino and Engström 1952, Amprino 1952, Jowsey, Owen and Vaughan 1953). Quantitative measurements have also been made of this variation in content of mineral salts using the microradiographic-photometric technique developed by Engström. Previous workers (Amprino and Engström 1952, Amprino 1952) have been particularly interested in the relative amounts of mineral salts in Haversian systems and have determined the variation of calcification within the systems themselves and with respect to their more highly calcified surroundings. Measurements made on sections from bones of a large number of species showed that the amount of mineral salts in the Haversian systems is from 0 to 20 per cent lower than their surroundings and that the more lowly calcified systems predominate in younger animals. Also the calcification within the systems themselves is not uniform and depends on the age of the system.

A detailed investigation has already been made of the growth and structure of the proximal half of the rabbit tibia from six weeks to seven months old using both microradiographic and autoradiographic techniques (Owen, Jowsey and Vaughan 1955). Microradiographs of serial transverse sections from the mid-shaft to just below the epiphysial plate of the tibia showed clearly, though qualitatively, that different structures in the bone have varying degrees of calcification. More quantitative measurements of these differences have been made, and will be described.

It was previously shown (Owen, Jowsey and Vaughan 1955) that the remains of epiphysial bone, which was presumably formed when the epiphysial plate was at a particular level, was to be found at practically all levels at all ages studied. Resorption cavities and developing Haversian systems at all stages of calcification (the latter having been formed within resorption cavities) were situated almost entirely within this epiphysial bone, indicating its gradual removal and replacement as part of the remodelling process. The epiphysial bone was of lower calcification than the bone later formed on its periosteal and endosteal surfaces and could easily be distinguished, especially in the older animals where there had been considerable deposition of new bone on these surfaces. (Endosteal bone actually being laid down at the time the animal was killed appeared as a narrow band of lowly calcified bone external to the older highly calcified endosteal bone.) Remnants of calcified cartilage were embedded in the epiphysial bone and these showed a much higher absorption of $\mathrm{x}$-rays than either the bone adjacent to them or the more recent periosteal and endosteal bone. These features are shown, for example, in Figure 1, which is a microradiograph of part of the internal wall of a section from the mid-shaft of a seven months old rabbit. In the present investigation measurements have been made of the relative content of mineral salts in calcified cartilage, bone immediately adjacent to the latter, and periosteal and endosteal bone, in rabbits which were six weeks, three and a half months, and seven months old.

\section{EXPERIMENTAL METHOD}

The experimental technique used is similar to that described by Engström and Welin (1949) and is briefly as follows. A microradiograph of both a transverse section of bone and 
a step-wedge of foils of known composition and thickness was obtained. By comparing photographic densities the absorption of a particular structure in the bone could then be obtained in terms of the thickness of the foil. Since the sensitivity of the photographic emulsion depends on the wavelength of the $\mathrm{x}$-rays, the step-wedge must be of a composition such that the same fraction of $x$-rays transmitted by various thicknesses of bone and foil has the same wavelength distribution over the range used. Using the composition of bone as given by Engström (1946) it was calculated that this condition was satisfied to within 1 per cent by aluminium foils for the present wavelength range-that is, the mass absorption coefficient of bone was for all practical purposes proportional to the mass absorption coefficient of aluminium over the wavelength range used.

To obtain microradiographs with good contrast between regions of bone containing different amounts of the calcium salt, it is preferable to use $\mathrm{x}$-rays of wavelength just less than $3.06 \mathrm{~A}$, which is the position of the $\mathrm{K}$-absorption edge for calcium. This is because,

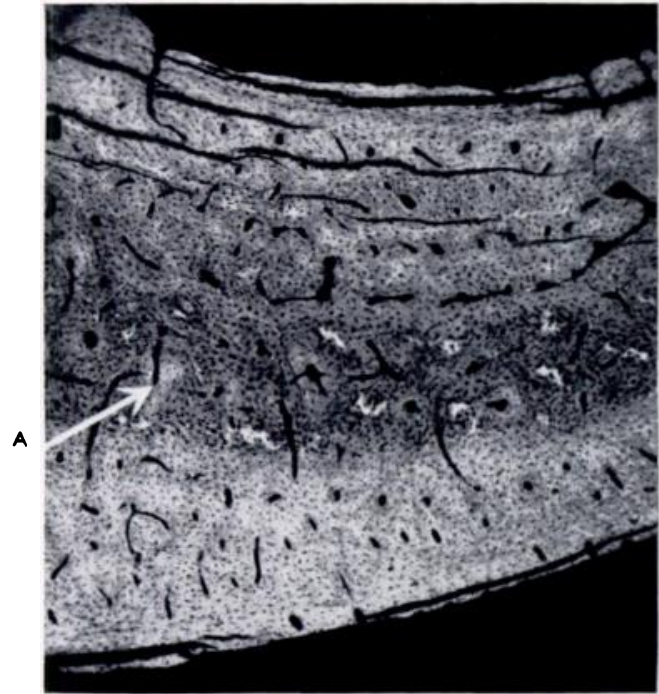

Fig. 1

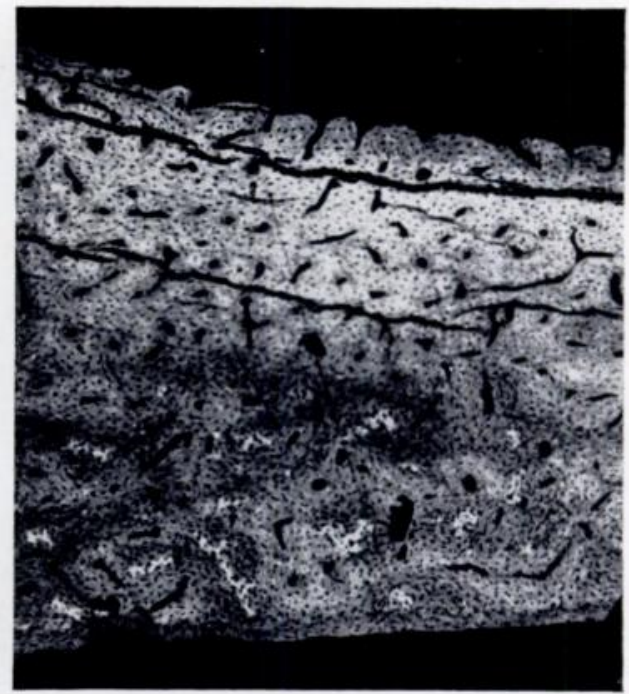

Fig. 2

Figure 1-Microradiograph of part of section of internal wall from midshaft of seven months old rabbit tibia. Note central band of epiphysial bone containing $a$ ) remnants of highly calcified cartilage, b) " bone adjacent to cartilage" showing low degree of calcification, c) several completed osteones (e.g., A) of higher degree of calcification. Note bands of highly calcified bone on periosteal (lower) and endosteal (upper) edges. ( $\times 50$.) Figure 2-Microradiograph of part of section of anterior wall from metaphysis of seven months old rabbit tibia. Note band of epiphysial bone on periosteal (lower) edge containing $a$ ) remnants of highly calcified cartilage, $b$ ) " bone adjacent to cartilage " showing low degree of calcification, $c$ ) completed osteones of higher degree of calcification. Note band of highly calcified bone on endosteal (upper) edge. $(\times 50$.)

for these $\mathrm{x}$-rays, the absorption coefficient for calcium is high compared with that for other constituents of bone. The same $x$-ray tube was used as in our previous work (Jowsey, Owen and Vaughan 1953). The microradiographs for the present measurements were obtained with $20 \mathrm{kev}$ radiation from a chrome target filtered through a 25 micron aluminium window. A graph of this radiation in roentgens as a function of wavelength is shown by curve $A$ in Figure 5. The amount of the radiation transmitted by "bone" (Engström 1946) and by aluminium was calculated; and, for the range of bone sections used (40 to 60 microns), 1) there was a linear relation between the thicknesses of bone and aluminium which transmitted the same fraction (to within 1 per cent) of the $\mathrm{x}$-rays; and 2) the wavelength distribution for the same fraction of transmitted radiation agreed closely for the two substances. A typical illustration of this is shown by curves B and C in Figure 5, which show the same fraction of $\mathrm{x}$-rays transmitted by 50 microns of bone and 33 microns of aluminium respectively. For

vol. 38 B, NO. 3, AUGUST 1956 
wavelengths less than $3.06 \AA$ the agreement was practically identical; for wavelengths greater than $3.06 \mathrm{~A}$ a small portion of $\mathrm{x}$-rays is transmitted by bone and not by aluminium. This was neglected, howcver, since it was always less than 1 per cent of the total. The absorption of $\mathrm{x}$-rays by various structures in the bone can therefore be compared directly in terms of the thicknesses of aluminium foil which absorb the same amount of $x$-rays. For the above radiation it can also be shown that the inorganic part of bone, which is commonly assumed

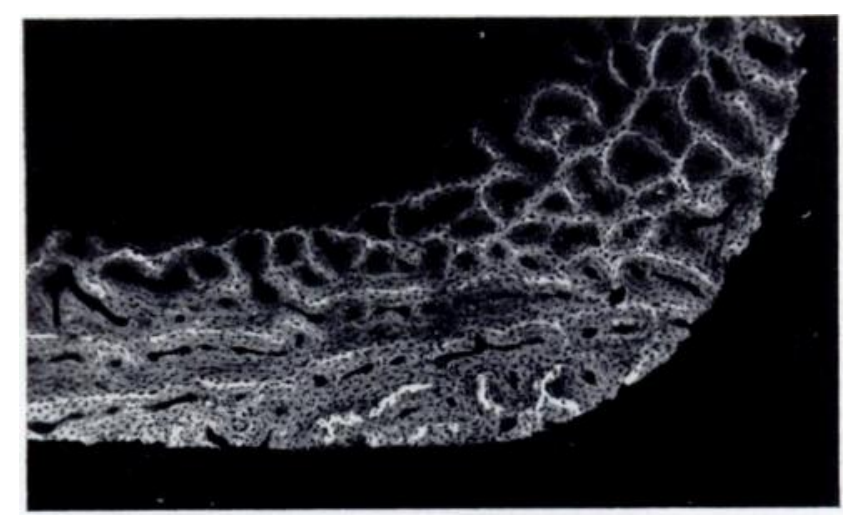

FIG. 3

Microradiograph of corner between internal and posterior walls from junction of metaphysis and shaft of six weeks old rabbit tibia. Remains of epiphysial bone containing highly calcified cartilage on periosteal side of corner. Active endosteal deposition; note highly calcified network enclosing Haversian systems of low calcification. $(\times 50$. $)$

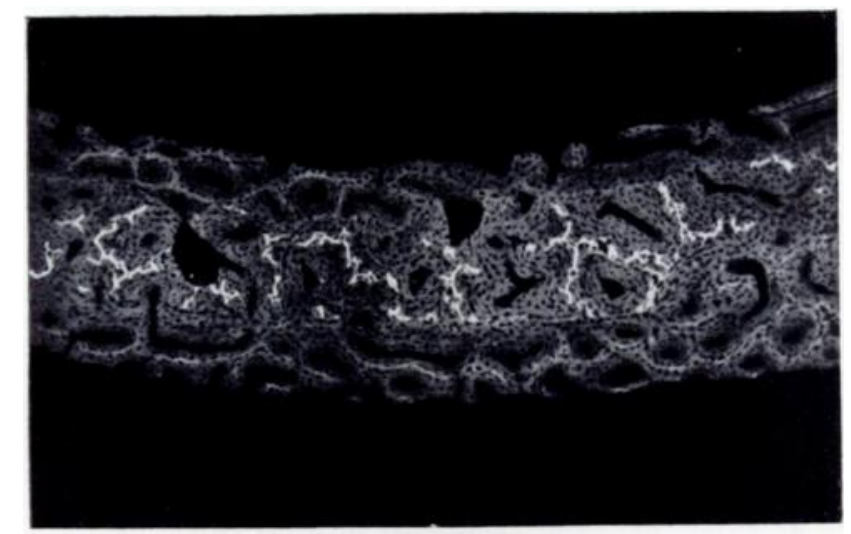

Fig. 4

Microradiograph of part of anterior wall from junction of metaphysis and shaft of six weeks old rabbit tibia. Mainly epiphysial bone containing remnants of highly calcified cartilage. Some periosteal and endosteal deposition. Note highly calcified network enclosing Haversian systems of low calcification. ( - 50.)

to be a hydroxy-apatite, accounted for about 90 per cent of the total amount of radiation absorbed in roentgens, the other 10 per cent being absorbed by the organic matrix. Differences in the absorption of the $\mathrm{x}$-rays are therefore due mainly to differences in the content of the mineral salt.

The rabbit tibiae were embedded in perspex. Sections about 100 microns thick were cut on a milling machine and then ground by hand under alcohol on ground glass to a thickness of about 50 microns. The section was placed alongside the step-wedge of aluminium 
foils (20, 30, 40, 60 and 80 microns thick) on a Kodak maximum resolution plate and pressed in contact with it. A sheet of Styrafoil (12 microns thick and for our purposes transparent to $\mathrm{x}$-rays) was placed over the top and screwed down with a brass ring to keep the section and step-wedge in position. It is necessary that the portion of the x-ray field used should be uniform, and in order that a large enough area should be available the plate was placed about 13 centimetres from the target. At this distance an area of approximately 0.5 by 0.7 centimetre was of uniform intensity to less than 1 per cent. The space between the $x$-ray window and the plate was evacuated. With a tube current of 220 microamps the exposure time was of the order of ten minutes. With these conditions the photographic densities on the microradiograph of the bone were in the range 1.0 to $1 \cdot 8$. After exposure the plates were developed for three

TABLE I

Measurement of Relative Calcification Expressed as the Ratio of X-Ray Absorption in Calcified Cartilage to “Bone Adjacent to Cartilage," Periosteal Bone and Endosteal Bone, in Different Parts of the Tibia from Rabbits of

Different Ages

\begin{tabular}{|c|c|c|c|}
\hline Age of rabbit & Position of section & \multicolumn{2}{|c|}{ Ratio of $x$-ray absorption in } \\
\hline 7 months & Mid-shaft & $\begin{array}{c}\text { Calcified cartilage } \\
\text { "Bone adjacent to cartilage" }\end{array}$ & $1 \cdot 19 \pm 0.03$ \\
\hline 7 months & Mid-shaft & $\begin{array}{l}\text { Calcified cartilage } \\
\text { Periosteal bone }\end{array}$ & $1.08=0.03$ \\
\hline 7 months & Metaphysis & $\begin{array}{c}\text { Calcified cartilage } \\
\text { " Bone adjacent to cartilage" }\end{array}$ & $1 \cdot 18 \pm 0.03$ \\
\hline 7 months & Metaphysis & $\begin{array}{l}\text { Calcified cartilage } \\
\text { Endosteal bone }\end{array}$ & $1.07 \mp 0.03$ \\
\hline $3 \frac{1}{2}$ months & Metaphysis & $\begin{array}{c}\text { Calcified cartilage } \\
\text { " Bone adjacent to cartilage" }\end{array}$ & $1 \cdot 18 \pm 0.04$ \\
\hline $3 \frac{1}{2}$ months & Metaphysis & $\frac{\text { Calcified cartilage }}{\text { Endosteal bone }}$ & $1 \cdot 10 \pm 0.03$ \\
\hline 6 weeks & Mid-shaft & $\begin{array}{l}\text { Calcified cartilage } \\
\text { Periosteal bone }\end{array}$ & $1 \cdot 11 \pm 0.04$ \\
\hline 6 weeks & Metaphysis & $\begin{array}{c}\text { Calcified cartilage } \\
\text { "Bone adjacent to cartilage" }\end{array}$ & $1 \cdot 24 \pm 0 \cdot 05$ \\
\hline 6 weeks & Metaphysis & $\begin{array}{l}\text { Calcified cartilage } \\
\text { Endosteal bone }\end{array}$ & $1.09 \pm 0.04$ \\
\hline
\end{tabular}

and a half minutes in Kodak D178 developer at a constant temperature of 20 degrees centigrade, washed and immersed in an acetic acid stop-bath for thirty seconds, fixed for fifteen minutes and finally washed for several hours.

Great care was taken in choosing the part of the bone section on which measurements were to be made. Preliminary microradiographs indicated the parts of the section which were most uniform in thickness and free from cracks or other artefacts. The thickness of the section was measured with a Baty comparator which had a measuring foot with a cross-section of diameter of 1 millimetre and which could be read to one micron. Only those parts of the section were chosen for measurement whose surroundings gave the same thickness reading to within a distance of 1 millimetre. Different structures in the bone section whose calcium salt content was being compared were never more than 300 microns apart, and it is unlikely that the thickness of the section varied over this distance. For a large number of measurements the comparator gave readings which were within \pm 2 per cent.

VOL. 38 B, NO. 3, AUGUST 1956 
The areas whose densities were to be measured on the microradiograph were of the order of 30 microns in diameter, hence a densitometer for determining the density of areas just less than 10 microns in diameter was constructed. A diagram of the instrument is shown in Figure 6. $\mathrm{L}$ is a light source giving a constant output, $\mathrm{C}$ is a condenser lens, the specimen $\mathrm{S}$ is a microradiograph, a magnified image of which is formed on the white screen $D$ by the lens $O$. The area on the microradiograph whose density is being measured is defined by a pinhole, half a millimetre in diameter, in the centre of the screen D. Light passes through the pinhole and is detected by the photomultiplier $\mathbf{P}$ giving a current reading on the galvanometer $\mathrm{G}$. The area on the microradiograph corresponding to that covered by the pinhole is just less

TABLE II

Measurement of Calcification Expressed in Terms of the Number of Microns of Aluminium foil which Absorb the Same amount of X-rays as a $50 \mu$ Thick Section of a Particular Structure of Bone

\begin{tabular}{|c|c|c|c|c|c|}
\hline $\begin{array}{l}\text { Age } \\
\text { of } \\
\text { rabbit }\end{array}$ & $\begin{array}{l}\text { Position } \\
\text { of } \\
\text { section }\end{array}$ & $\begin{array}{l}\text { Number of } \\
\text { sections } \\
\text { measured }\end{array}$ & $\begin{array}{c}\text { Total } \\
\text { number of } \\
\text { measurements }\end{array}$ & Bone structure & $\begin{array}{l}\text { Microns of } \\
\text { aluminium } \\
\text { equivalent to } \\
50 \text { microns } \\
\text { of bone }\end{array}$ \\
\hline 7 months & Mid-shaft & 3 & 12 & Calcified cartilage & $48.9=1.9$ \\
\hline 7 months & Mid-shaft & 3 & 15 & "Bone adjacent to cartilage" & $41 \cdot 5=1 \cdot 8$ \\
\hline 7 months & Mid-shaft & 3 & 33 & Periosteal bone & $45 \cdot 4 \div 1 \cdot 7$ \\
\hline 7 months & Metaphysis & 3 & 21 & Calcified cartilage & $48 \cdot 4 \div 1.9$ \\
\hline 7 months & Metaphysis & 3 & 35 & "Bone adjacent to cartilage" & $40 \cdot 6=2 \cdot 0$ \\
\hline 7 months & Metaphysis & 3 & 36 & Endosteal bone & $45 \cdot 2=1 \cdot 7$ \\
\hline $3 \frac{1}{2}$ months & Mid-shaft & 1 & 10 & Periosteal bone & $43 \cdot 3 \div 2 \cdot 0$ \\
\hline $3 \frac{1}{2}$ months & Metaphysis & 2 & 9 & Calcified cartilage & $49 \cdot 0=2 \cdot 0$ \\
\hline $3 \frac{1}{2}$ months & Metaphysis & 2 & 11 & "Bone adjacent to cartilage" & $41 \cdot 6: 1 \cdot 8$ \\
\hline $3 \frac{1}{2}$ months & Metaphysis & 2 & 10 & Endosteal bone & $44 \cdot 4 \div 2 \cdot 0$ \\
\hline 6 weeks & Mid-shaft & 2 & 10 & Calcified cartilage & $47 \cdot 3 \div 2 \cdot 0$ \\
\hline 6 weeks & Mid-shaft & 2 & 11 & Periosteal bone & $42 \cdot 5=2 \cdot 1$ \\
\hline 6 weeks & Metaphysis & 3 & 12 & Calcified cartilage & $48.0 \div 1.7$ \\
\hline 6 weeks & Metaphysis & 2 & 10 & "Bone adjacent to cartilage" & $39 \cdot 0 \div 2 \cdot 0$ \\
\hline 6 weeks & Metaphysis & 2 & 12 & Endosteal bone & $44 \cdot 3: 2 \cdot 0$ \\
\hline
\end{tabular}

than 10 microns in diameter and it can be seen in the mirror $\mathrm{M}$ via the viewing tube $\mathrm{V}$. The density of a structure on the microradiograph was determined by comparison with the calibrated annular density wedge $A$ which has a continuous variation from 0 to 3 over 360 degrees. Its position could be read on the graduated disc $\mathrm{Q}$.

When measuring the photographic density corresponding to a particular structure of bone many readings were taken and averaged. This was necessary because there was a spread in the density measurements of up to 3 per cent due to the fact that even bone within the same structure is not homogeneous. For each plate a graph of D (photographic density) versus thickness of aluminium foil in microns was plotted. A typical example is shown in Figure 7. From this the absorption of a particular bone structure could be read off in terms of microns of aluminium foil. The error in measuring the photographic density was \pm 1 per 
cent. With the present microradiographs it was therefore estimated that a variation of \pm 1.5 per cent in the absorption of $\mathrm{x}$-rays by bone could be detected.

\section{RESULTS}

The measurements made of the relative content of mineral salt in different parts of the bone have been expressed in the present study in two different ways. 1) As a ratio of the absorption of $\mathrm{x}$-rays by the highly calcified cartilage to the absorption by other parts of bonenamely $a$ ) "bone adjacent to cartilage" (that is, epiphysial bone laid down on the highly calcified cartilage); $b$ ) periosteal bone; $c$ ) endosteal bone (Table I; Figs. 1 to 4 ) (that is, bone laid down on these surfaces around small vessels or marrow spaces). Since these ratios are derived from measurements made on the same plate they do not depend on measurements of

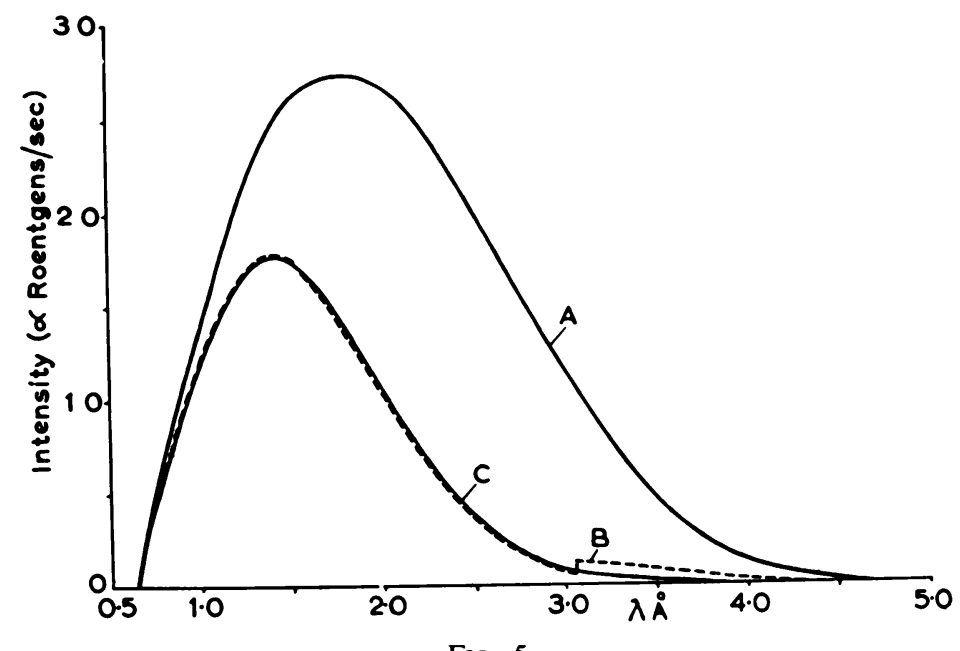

Fig. 5

Curve A shows the amount of $20 \mathrm{kev}$ radiation in roentgens (arbitrary units) from a chrome target filtered by 25 microns aluminium. Curves B and $C$ are for the same radiation transmitted through 50 microns of " bone " and 33 microns of aluminium respectively.

the section thickness. 2) In terms of the number of microns of aluminium foil that absorb the same amount of $\mathrm{x}$-rays as a 50 micron thick section of a particular structure of bone (Table II). Assuming that rabbit bone has the same composition as that given by Engström, the average density of the bone structure can also be calculated from the present measurements, and for periosteal and endosteal bone in Table II this was 2.08 grammes per cubic centimetre. The errors in Table II include the 2 per cent error in measurement of the section thickness. The results given in the Tables are for the absorption of $\mathrm{x}$-rays by both the inorganic and organic components of bone. A recent paper (Davies and Engström 1954) has shown that the amount of organic matrix is the same in both "young" and "old " Haversian systems even though they have different degrees of calcification. Assuming that the different structures observed here contain the same amount of organic matrix, then any difference in the absorption of $x$-rays is entirely due to differences in content of the inorganic salt. When allowance is made for the fact that a small fraction of $\mathrm{x}$-rays is absorbed by the organic matrix the ratios in Table I are found to be increased by between 1-3 per cent. This is insignificant for the purposes of the present discussion and does not alter the values in Table II enough to affect the comparison between them that is given below.

As can be seen from Table I the ratio of $\mathrm{x}$-ray absorption by calcified cartilage to that by " bone adjacent to cartilage" and to periosteal and endosteal bone are the same within

vol. 38 B, No. 3, AUGUST 1956 
the experimental errors for rabbits of the three age groups. The absorption of $x$-rays by remnants of calcified cartilage found in both the mid-shaft and the metaphysis is the same within the errors for all three ages (Table II). " Bone adjacent to cartilage" was also calcified to about the same extent at all levels and all ages (Table II). It was noted that periosteal and endosteal bone is not evenly calcified but is more highly calcified in the spaces between the small Haversian systems (Figs. 1 to 4). All the values quoted in Tables I and II were from measurements made on these more highly calcified interstitial areas and within the errors are the same at all levels in all rabbits. In the older rabbits, three and a half months and seven months, the degree of calcification of the small Haversian systems in periosteal and endosteal bone varied only slightly from that of the spaces between them (Figs. 1 and 2). However, in the six weeks old animal where deposition of bone on the periosteal and endosteal surfaces is very active (Figs. 3 and 4), the bone surrounding the vessels or small marrow spaces is about 10-15 per cent less calcified than the bone laid down first, i.e., the network of bone in the interstitial areas between the systems. The latter have, within the errors, the same

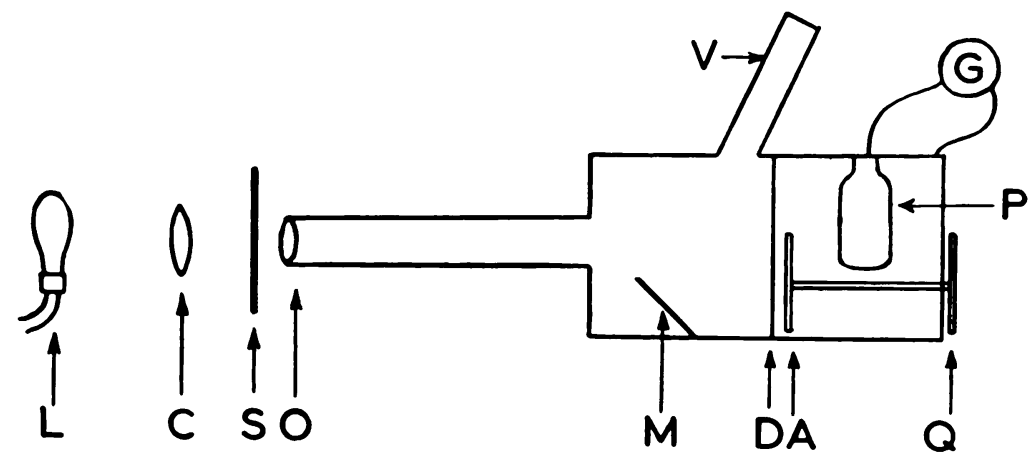

FIG. 6

Diagram of densitometer (see text).

calcification as bone in a similar position in the older animal. From autoradiographic studies of the uptake of $\mathrm{Sr}^{90}$ it is evident that, in the young animal, bone is being deposited very rapidly around these small vascular spaces on the periosteal and endosteal surfaces (Owen, Jowsey and Vaughan 1955) and it is likely that they quickly become highly calcified.

The major portion of seven months old bone consists of the periosteal bone deposited in the shaft and the endosteal bone deposited in the metaphysis (Owen, Jowsey and Vaughan 1955). At seven months the Haversian canals are on the whole smaller than in the very young animal and the bone has a more solid appearance and a fairly even degree of calcification. In bone from rabbits of this age, particularly, there was evidence that the more lowly calcified epiphysial bone had in some parts been replaced by completed osteones of the same degree of calcification as the neighbouring more highly calcified periosteal and endosteal bone, for example osteone $\mathrm{A}$ in Figure 1. These completed osteones are presumably Haversian systems which have been formed within a resorption cavity and which have gradually attained a high degree of calcification. Probably most of the epiphysial bone is gradually removed and replaced in this way during the life of the animal (Jowsey, Owen, Tutt and Vaughan 1955).

Two general conclusions may be drawn from the measurements recorded. 1) The bone of both young and adult rabbit has a framework of approximately the same strength or degree of calcification-that is, the supporting calcified cartilage formed below the epiphysial plate and the bone in the spaces between the small Haversian systems or vessels of periosteal and endosteal bone have the same degree of calcification in both young and adult rabbits. 
2) There appears to be a trend towards uniform calcification throughout adult bone which is of the order of calcification of the interstitial areas of periosteal and endosteal bone. Evidence for this is the removal of lowly calcified epiphysial bone and its replacement by more highly calcified osteones.

\section{SUMMARY}

1. Measurements have been made of the relative calcification of different types of bone in tibia of the rabbit at the ages of six weeks, three and a half months and seven months by comparing their absorption of $\mathrm{x}$-rays.

2. Calcified cartilage is between 8 and 10 per cent more highly calcified than periosteal and endosteal bone and about 20 per cent more highly calcified than bone formed immediately adjacent to cartilage.

3. Young and adult bones have a framework of approximately the same strength; that is, calcified cartilage, bone adjacent to cartilage and the interstitial areas of periosteal and endosteal bone have each approximately the same degree of calcification at all ages.

4. Adult rabbit bone approaches uniform calcification throughout, equal to the calcification of the interstitial areas of periosteal and endosteal bone. Evidence for this is the replacement of the lowly calcified epiphysial bone by osteones of higher calcification.

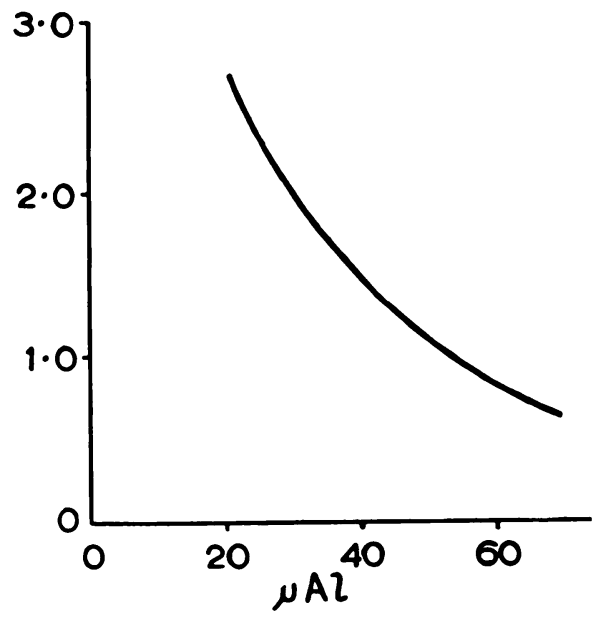

FIG. 7

Graph of density on photographic plate due to $20 \mathrm{kev} x$-rays transmitted by various thicknesses of aluminium in microns.

I am indebted to Dr D. G. Wyatt and Dr Janet Vaughan for advice and criticism.

This work was begun on behalf of the Protection Sub-Committee of the Medical Research Council's Committee on Medical and Biological Applications of Nuclear Physics. The expenses were defrayed from a personal grant to Dr Janet Vaughan.

\section{REFERENCES}

AMpRINo, R. (1952): Rapporti fra processi di ricostruzione e distribuzione dei minerali nelle ossa. I. Ricerche eseguite col metodo di studio dell' assorbimento dei raggi Roentgen. II. Ricerche con metodo autoradiografico. Zeitschrift für Zellforschung, 37, 144, 240.

Amprino, R. (1952): Autoradiographic Analysis of the Distribution of Labelled Ca and P in Bones. Experientia, 8, 20.

Amprino, R., and Engström, A. (1952): Studies on X Ray Absorption and Diffraction of Bone Tissue. Acta Anatomica, 15, 1.

Davies, H. G., and Engström, A. (1954): Interferometric and X-ray Absorption Studies of Bone Tissue. Experimental Cell Research, 7, 243.

ENGSTRÖM, A. (1946): Quantitative Micro- and Histochemical Elementary Analysis by Roentgen Absorption Spectrography. Acta Radiologica, Supplement 63.

EngStröm, A., and Welin, S. (1949): A Method for the Quantitative Roentgenological Determination of the Amount of Calcium Salts in Bone Tissue. Acta Radiologica, 31, 483.

Jowsey, J., Owen, M., and Vaughan, J. (1953): Microradiographs and Autoradiographs of Cortical Bone from Monkeys injected with ${ }^{90} \mathrm{Sr}$. British Journal of Experimental Pathology, 34, 661.

Jowsey, J., Owen, M., Tutt, M., and Vaughan, J. (1955): Retention and Excretion of ${ }^{90}$ Sr by Old Rabbits. British Journal of Experimental Pathology, 36, 22.

Owen, M., Jowsey, J., and VAughan, J. (1955): Investigation of the Growth and Structure of the Tibia of the Rabbit by Microradiographic and Autoradiographic Techniques. Journal of Bone and Joint Surgery, 37-B, 324.

VOL. 38 B, No. 3, AUGUSt 1956 